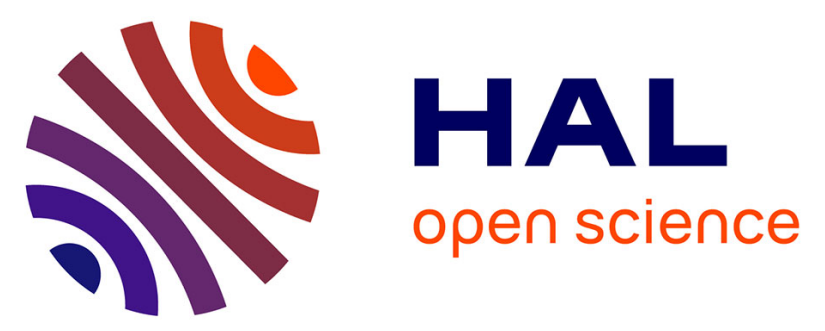

\title{
Probing the growth window of LaVO3 perovskites thin films elaborated using magnetron co-sputtering
}

C. Celindano, E. Haye, S. Bruyère, Pascal Boulet, A. Boileau, S. Migot, S. Mathieu, P. Miska, S. Barrat, F. Capon

\section{- To cite this version:}

C. Celindano, E. Haye, S. Bruyère, Pascal Boulet, A. Boileau, et al.. Probing the growth window of LaVO3 perovskites thin films elaborated using magnetron co-sputtering. Ceramics International, 2019, 45 (13), pp.16658-16665. 10.1016/j.ceramint.2019.05.208 . hal-02278538

\section{HAL Id: hal-02278538 \\ https://hal.science/hal-02278538}

Submitted on 25 Oct 2021

HAL is a multi-disciplinary open access archive for the deposit and dissemination of scientific research documents, whether they are published or not. The documents may come from teaching and research institutions in France or abroad, or from public or private research centers.
L'archive ouverte pluridisciplinaire HAL, est destinée au dépôt et à la diffusion de documents scientifiques de niveau recherche, publiés ou non, émanant des établissements d'enseignement et de recherche français ou étrangers, des laboratoires publics ou privés.

\section{()ㅜ(1)}

Distributed under a Creative Commons Attribution - NonCommerciall 4.0 International 


\title{
Probing the growth window of $\mathrm{LaVO}_{3}$ perovskites thin films elaborated using magnetron co-sputtering
}

\author{
Christophe Celindano ${ }^{\mathrm{a}, *}$, Emile Haye ${ }^{\mathrm{b}}$, Stéphanie Bruyère $^{\mathrm{a}}$, Pascal Boulet $^{\mathrm{a}}$, Alexis Boileau ${ }^{\mathrm{c}}$ \\ Sylvie Migot ${ }^{a}$, Sandrine Mathieu ${ }^{\mathrm{a}}$, Patrice Miska ${ }^{\mathrm{a}}$, Silvère Barrat ${ }^{\mathrm{a}}$, Fabien Capon ${ }^{\mathrm{a}}$ \\ ${ }^{a}$ Université de Lorraine, IJL, CNRS, F-54000 Nancy, France \\ ${ }^{b}$ Laboratoire Interdisciplinaire de Spectroscopie Electronique (LISE), Namur Institute of Structured Matter \\ (NISM), University of Namur, 61 Rue de Bruxelles, 5000 Namur, Belgium \\ ${ }^{c}$ CRISMAT, CNRS UMR6508, ENSICAEN, Normandie Université, 14050 Caen Cedex 4, France
}

\begin{abstract}
$\mathrm{LaVO}_{3}$ is a promising material for tuning and improving solar cell performances when modifying the La/V stoichiometry. However, the production of $\mathrm{LaVO}_{3}$ thin films still requires a complex process (MBE, PLD), and the growth window of $\mathrm{LaVO}_{3}$ structure in terms of $\mathrm{La} / \mathrm{V}$ ratio, already defined in the literature using hybrid-MBE is not determined for elaboration based on magnetron co-sputtering of both vanadium and lanthanum targets followed by an external reducing annealing that we use here. La/V ratio has been varied from 0.52 to 1.68 by changing the power applied to the vanadium target in order to synthesize films with different La/V ratios. The off-stoichiometry growth window has been investigated by complementary methods (XRD, XPS, FTIR and TEM). X-ray diffraction highlights the $\mathrm{LaVO}_{3}$ structure for all the films. For La-rich samples (La/V ratio $>1.2$ ), the formation of lanthanum oxide $\mathrm{La}_{2} \mathrm{O}_{3}$ is observed at the top surface and interface with the substrate, according to XPS, FTIR and TEM investigations. On the other hand, for V-rich samples, only a slight modification of the structure is observed below the La/V ratio $=0.6$; with the presence of a new IR vibration mode corresponding to a small contribution of vanadium oxide(s) present in volume. Our study allows a better definition of the $\mathrm{LaVO}_{3}$ growth window in terms of $\mathrm{La} / \mathrm{V}$ ratio, estimated from 0.6 to 1.2 .

Keywords: Oxide, Thin film, Sputtering, Crystallization, Vanadate, Perovskite
\end{abstract}

Declarations of interest: none

*Corresponding author
Email address: christophe.celindano@univ-lorraine.fr (Christophe Celindano) 


\section{Introduction}

The conventional solar cells have a limited energy conversion efficiency because photons with energies lower than the band gap are not absorbed and those with higher energies mainly produce phonons. One of the possible ways to circumvent this problem is the use of multi-junctions with several layers that cover a larger part of the solar spectrum. In this way, Mott insulators as solarabsorbers using carrier multiplication could be considered [1]. Indeed, lanthanum vanadate $\mathrm{LaVO}_{3}$ is a promising candidate with an indirect forbidden band gap close to $1.1 \mathrm{eV}$ [2], i.e. close to the ShockleyQueisser limit [3] and a good absorption coefficient [4]. This perovskite material and more especially the off-stoichiometry $\mathrm{La}_{1+x} \mathrm{VO}_{3}$ films have already been studied for photovoltaic solar applications $[5,6]$ but mainly by a hybrid molecular beam epitaxy growth method. In such an approach, the authors investigated the off-stoichiometry $\mathrm{LaVO}_{3}$ samples by varying $\mathrm{La} / \mathrm{V}$ ratio during the synthesis. However, most of the studies deal with lanthanum over-stoichiometry, in a small range of concentration. The effect of $\mathrm{La} / \mathrm{V}$ ratio variation over a wide range in $\mathrm{LaVO}_{3}$ remains an open question.

Usually, lanthanum vanadate films are deposited by pulsed laser deposition, molecular beam epitaxy or are synthesized through powder reactions of lanthanum and vanadium oxides $[7,8,9,10$, 11, 12]. These growth processes are limited in terms of upscaling concerns. Therefore, by focusing here on the sputtering technique, we use an alternative way for the synthesis of crystalline $\mathrm{LaVO}_{3}$. The synthesis is based on a two-step process with 1) deposition of a LaVO thin-film by magnetron co-sputtering and 2) ex-situ annealing under a reducing atmosphere. Such a process is easy to up-scale for large surfaces treatments as required for many industrial applications.

For possible use in photovoltaics, the goal of the present paper is to extend the present knowledge about the growth of LaVO3 using magnetron sputtering, particularly by determining $\mathrm{LaVO}_{3}$ growth window where no formation of additional phases is observed. In this view, thin films with different $\mathrm{La} / \mathrm{V}$ atomic ratios (from 0.52 to 1.68 ) are obtained adapting the sputtering electrical parameters and analyzed using X-ray diffraction (XRD), X-ray photoelectron spectroscopy (XPS), transmission electron microscope (TEM) and infrared spectroscopy. 


\section{Experimental section}

L sputtering chamber connected to a turbomolecular secondary pump backed by a rotary pump to get a vacuum close to $5 \cdot 10^{-5} \mathrm{~Pa}$ before each deposition process. Two inches diameter lanthanum and vanadium targets with atomic purity of $99.9 \%$ are used for the co-sputtering. The targets are surrounded by plasma suppressors and separated by a distance of $80 \mathrm{~mm}$, long enough to avoid any on a rotating holder and located at $55 \mathrm{~mm}$ and $70 \mathrm{~mm}$ away from respectively the lanthanum and vanadium targets. Discharge parameters have been optimized from previous works using similar elements $[13,14,15,16,17,18]$. The lanthanum target is powered by an Advanced Energy Pinnacle $5 \mathrm{~kW}$ pulsed-DC generator under a power regulation of $75 \mathrm{~W}$, a frequency of $100 \mathrm{kHz}$ and an off-time a pre-chosen and fixed power ranging from 200 to $300 \mathrm{~W}$. The pressure control is established by using an MKS Baratron 627 capacitive gage with a $1.33 \mathrm{hPa}$ range and the gas are flown (at 21 sccm for argon and varying flow for the oxygen) using Alphagaz RDM 280 flowmeters. Substrates temperature is evaluated by using a thermocouple, located inside the substrates holder.

Prior to the deposition, the substrates used are cleaned with acetone and ethanol, followed by insitu by reactive-ion etching (RIE) with an Advanced Energy Cesar radiofrequency (RF) generator inside the sputtering chamber for 5 minutes under gas flows close to the growth conditions (i.e. under $21 \mathrm{sccm}$ of $\mathrm{Ar}$ and $7 \mathrm{sccm}$ of $\mathrm{O}_{2}$ ).

Two types of annealing treatments have been tested to crystallize the perovskite, namely an air annealing and a reducing annealing. The first annealing is carried out in the air and performed with a Barnstead type 47900 furnace at $900{ }^{\circ} \mathrm{C}$ for $5 \mathrm{~min}$. For the second annealing, a homemade furnace is used for the post-growth annealing step, composed of a quartz cylinder receiving a sample-holder where a primary vacuum is done before the heating step. The annealing temperature is regulated with an Eurotherm temperature regulator while the gas flows are controlled via a MKS Type 647C before each use. in a gaseous mixture of $90 \% \mathrm{Ar}$ and $10 \% \mathrm{H}_{2}$ working pressure is fixed at 700 torr and a temperature ramp has been fixed, with a temperature of $900{ }^{\circ} \mathrm{C}$, reached in 90 min and kept constant for $60 \mathrm{~min}$. When the cycle ends, gas flows are set to zero and the quartz chamber is isolated, with a static pressure imposed by the amount of remaining gas. Samples are then cooled 
to ambient temperature in almost six or seven hours.

FEI/Philips XL-30 field emission environmental scanning electron microscope (ESEM) working at $15 \mathrm{kV}$ provides X-ray energy dispersive spectroscopy (EDS) measurements, useful for the La/V atomic ratio estimation of the different samples with a thickness varying between 200 and $300 \mathrm{~nm}$. Analyzing thin films, the composition estimation is reliable for studying an atomic ratio evolution, not in absolute value.

The chemical composition of the $\mathrm{La}_{x} \mathrm{~V}_{y} \mathrm{O}_{3}$ thin films have been investigated by XPS (K-Alpha Thermo Scientific spectrometer) using a monochromatic Al K alpha radiation (1486.68 eV). The X-rays spot size was $250 \mu \mathrm{m}$ in diameter. Spectra (La 3d, O 1s and V 2p) have been recorded with an energy resolution of $0.5 \mathrm{eV}$ and a pass energy of $20 \mathrm{eV}$. The number of scans was adjusted (between 5 and 30 scans) for each element to get similar signal-to-noise ratios. A flood gun was used for the charge compensation and spectra were calibrated by fixing the La $3 \mathrm{~d} 5 / 2$ main peak at $833.6 \mathrm{eV}$, as the intensity of the adventitious carbon peak was too weak, and the La $3 \mathrm{~d} 5 / 2$ peak does not exhibit significant shift [19]. Peak-fitting was performed with the Avantage software (Thermo Scientific).

The structure of the sample is investigated by XRD with a Brucker D8 Advance diffractometer $\left(\lambda_{C u K \alpha 1}=1.54056 \AA\right)$ using the Bragg-Brentano $\theta-2 \theta$ configuration.

A doubly corrected JEOL ACCEL ARM Cold FEG 200F TEM coupled with a GATAN GIF Quantum ER was used in scanning transmission electronic microscopy (STEM) mode for Electron Energy Loss Spectroscopy (EELS) measurements (energy dispersion of $0.1 \mathrm{eV} / \mathrm{channel}$, a full width at half maximum (FWHM) of $0.6 \mathrm{eV}$, a $2 \mathrm{~nm}$ pixelsize and a pixeltime of $0.5 \mathrm{~s} /$ pixel to avoid beam damage). Fast Fourier transform (FFT) of high resolution transmission electron microscopy (HRTEM) images were recorded to obtain the crystallographic structure. Thin foils of selected samples were prepared by the focused ion beam (FIB) technique using a FEI HELIOS NanoLab 600i FIB/SEM.

\section{Results and discussion}

\subsection{Discharge characteristic}

The sputtering of lanthanum and vanadium in the presence of a reactive atmosphere has been investigated using hysteresis experiments, by sputtering each target separately or simultaneously. 
The parameters used are the further deposition parameters given in the table 1 except that for $\mathrm{O}_{2}$ flow rate. Before the hysteresis experiments, targets are sputtered in pure Ar gas for half an hour using the previous given parameters in order to avoid residual oxides and start the hysteresis experiments with metallic elements.

Figure 1 shows the oxygen partial pressure behavior as a function of the $\mathrm{O}_{2}$ flow rate using single sputtering (targets sputtered separately, Figure 1.a and 1.b) and the co-sputtering (Figures 1.c). The oxygen partial pressure is obtained by making the difference of total pressures measured with or without oxygen. In the absence of oxygen, pure metallic atoms are sputtered from the targets, which is often called the elemental sputtering mode (ESM) [20]. When oxygen is introduced in the chamber, this leads to a target poisoning caused by both chemisorption and ion implantation of fully covered by an oxide layer when the oxygen pressure starts to increase linearly with the $\mathrm{O}_{2}$ flow rate i.e. around $2 \mathrm{sccm} \mathrm{O}_{2}$ flow rate (see point A in Figure 1) leading to a regime where only compounds are sputtered and called reactive sputtering mode (RSM). For the vanadium target the transition occurs for an $\mathrm{O}_{2}$ flow rate higher than $4 \mathrm{sccm}$ (see point $\mathrm{B}$ in Figure 1.b) then, taken separately, the lanthanum is more reactive in an oxygen atmosphere than the vanadium.

When targets are sputtered together, the hysteresis curve (see point C Figure 1.c) is very similar to the vanadium one indicating that the simultaneous sputtering is driven by the vanadium element because even more reactive, the lanthanum target is still sputtered in ESM until the vanadium target becomes fully oxidized on the surface and then both targets are sputtered in RSM. At $10 \mathrm{sccm}$, the $\mathrm{O}_{2}$ flow rate is slowly decreased to zero (backward direction of the hysteresis) but the RSM is still effective for $\mathrm{O}_{2}$ flow rates lower than before for simple and co-sputtering (see points $\mathrm{D}, \mathrm{E}$ and F in Figure 1). This could be explained by the fact that despite the reduction of oxygen content, targets are still oxidized and become metallic only for smaller $\mathrm{O}_{2}$ flow rates.

Further, this result implies that changing the deposition parameters is more efficient by modifying the vanadium parameters than the lanthanum ones. Next, the choice is made to change the discharge power applied to the vanadium target. 
(a)
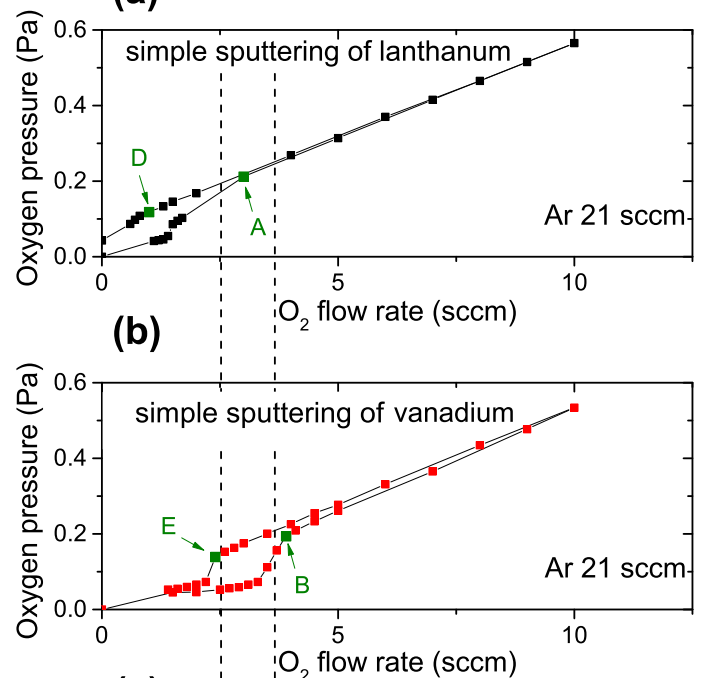

(c)

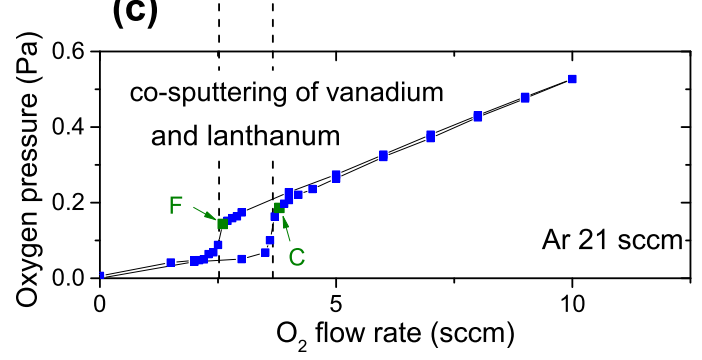

Figure 1: Oxygen partial pressure vs the oxygen flow rate of the hysteresis experiment for the sputtering of (a) the lanthanum target, (b) the vanadium target and (c) both targets together.

\subsection{Elaboration and annealing of $L a_{x} V_{y} O_{3}$ thin films}

The deposition parameters are given in table 1. The discharge power applied to the vanadium target is changed from 200 to $300 \mathrm{~W}$ inducing the modification of the La/V ratio.

As-deposited thin films are amorphous as observed by XRD in Figure 2. An annealing step is necessary to crystallize the perovskite-phase [22]. We first used an annealing made under air at $900{ }^{\circ} \mathrm{C}$ for $5 \mathrm{~min}$ inducing the formation of $\mathrm{LaVO}_{4}$ structure (Figure 2), where the vanadium has $\mathrm{a}+\mathrm{V}$ oxidation state. Consequently, reaching the $+\mathrm{III}$ oxidation state for the vanadium in $\mathrm{LaVO}_{3}$ 
Table 1: Experimental parameters for the elaboration of the samples by magnetron sputtering

\begin{tabular}{lcr} 
Parameter & value & unit \\
\hline Ar flow & 21 & $\mathrm{sccm}$ \\
O flow & 7 & $\mathrm{sccm}$ \\
Working pressure & 1.5 & $\mathrm{~Pa}$ \\
$\mathrm{P}_{V}$ (DC) & variable & $\mathrm{W}$ \\
V target distance & 7 & $\mathrm{~cm}$ \\
$\mathrm{P}_{L a}$ (DC-pulsed) & 75 & $\mathrm{~W}$ \\
$\mathrm{f}_{L a}$ & 100 & $\mathrm{kHz}$ \\
Toff $_{L a}$ & 4 & $\mu \mathrm{s}$ \\
La target distance & 5.5 & $\mathrm{~cm}$ \\
Substrates temperature & $\approx 60$ & ${ }^{\circ} \mathrm{C}$
\end{tabular}

requires a post-growth annealing treatment under an $\mathrm{Ar} / \mathrm{H}_{2}$ (100/10 sccm respectively ) reducing atmosphere.

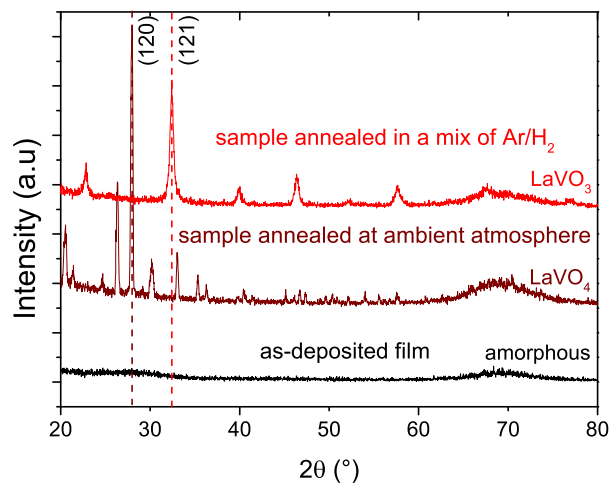

Figure 2: Diffractograms for a sample with a La/v ratio close to 1. As deposited film is amorphous whereas an ex-situ annealing leads to $\mathrm{LaVO}_{4}$ or $\mathrm{LaVO}_{3}$ depending on the annealing atmosphere (air or $\mathrm{Ar} / \mathrm{H}_{2}$ mixture).

The air annealing is then replaced by a reducing annealing process, performed under pumping while injecting $\mathrm{Ar} / \mathrm{H}_{2}$ gas mixture. For all samples, SEM cross-sections performed on both preand post-annealed steps (see Figure 3) show a morphological modification, from dense (for an asdeposited sample in Figure 3.a) to porous (after annealing in Figure 3.b) reducing the thickness of 

losses during the annealing.

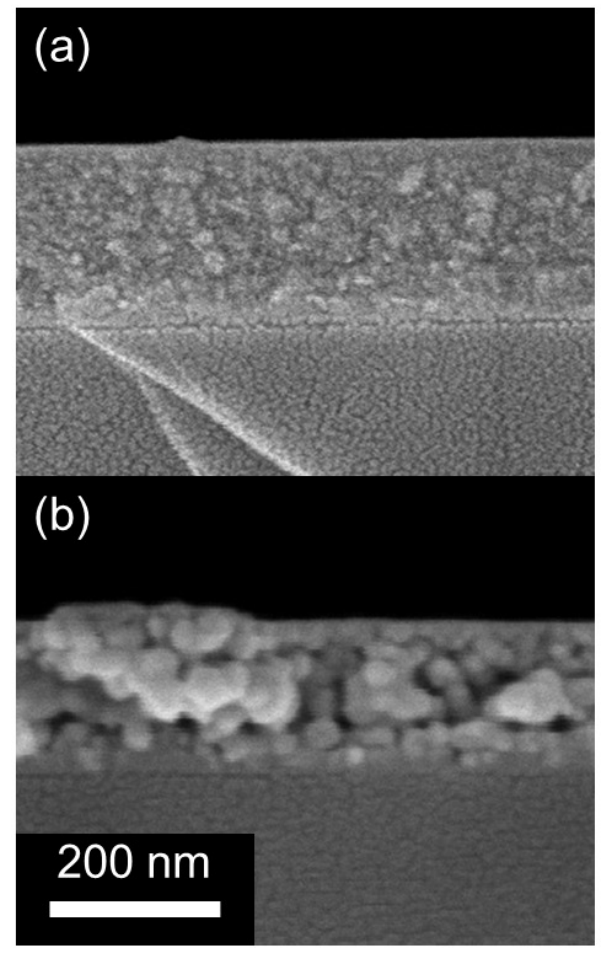

Figure 3: Layer morphology observed with the SEM high-resolution mode in cross-section at a working distance of $5 \mathrm{~mm}$, for a $3 \mathrm{kV}$ acceleration voltage and a 200k magnification. The $\mathrm{La} / \mathrm{V}$ ratio is around 1.68 in this case. Micrograph (a) shows cross-section of the as-deposited film and (b) after the reducing annealing.

\subsection{Growth window of $\mathrm{LaVO}_{3}$}

$\mathrm{La} / \mathrm{V}$ atomic ratio, evaluated by EDS measurement and which is not varying with the reducing annealing step, exhibits a linear evolution as a function of the discharge power applied to the vanadium target (see Figure 4).

Figure 5 shows the diffractograms from XRD measurements after reducing annealing. All the films present $\mathrm{LaVO}_{3}$ orthorhombic structure [23] with the space group Pnma (62). Beyond the $\mathrm{La} / \mathrm{V}$ value of 1.22 , a crystallized $\mathrm{La}_{2} \mathrm{O}_{3}$ cubic phase [24] appears in addition to the orthorhombic $\mathrm{LaVO}_{3}$ with two peaks at $28.7^{\circ}$ and $31.2^{\circ}$. 


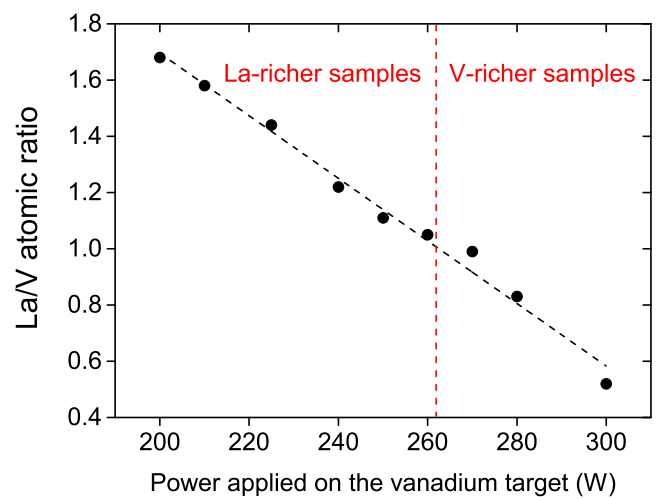

Figure 4: Evolution of the La/V atomic ratio (estimated using EDS) varying the power applied on the vanadium target. Power on the lanthanum target is kept constant and other parameters are given in table 1.

To obtain more information about the chemical composition, XPS Spectra were recorded between 510 and $535 \mathrm{eV}$ and are reported in Figure 6.a in order to obtain both $\mathrm{O}$ 1s and $\mathrm{V} 2 \mathrm{p}$ core levels for the different La/V ratios. As the $\mathrm{O}$ 1s and V 2p levels are near, they have been recorded and fitted with a unique background, as suggested by Biesinger [25]. The peak fitting is shown in Figure 6.c: O 1s signal presents two contributions, centered at 528.8 and $530.7 \mathrm{eV}$, corresponding to O-La and $\mathrm{O}-\mathrm{V}$ binding energies respectively. The $\mathrm{V} 2 \mathrm{p}$ signal exhibits two peaks corresponding to $3 / 2$ and $1 / 2$ spin-orbit splitting, with an energy difference of $7.5 \mathrm{eV}$. It appears that several contributions have to be used to fit these peaks, indicating different oxidation states of vanadium as previously reported $[26,27]$. Three contributions have been used for the $\mathrm{V} 2 \mathrm{p}^{3 / 2}$ peak fitting, centered at 514.1, 515.6 and $516.2 \mathrm{eV}$, that corresponds to +II, +III and +IV vanadium oxidation states. As La/V ratio increases, two major effects occur. First, the O-V binding contribution extinguishes (see Figure 6.a) due to the lower concentration of vanadium at the surface. Contrary to previous works dealing with $\mathrm{LaVO}_{3}$ elaborated by PLD [27, 28, 29], the O-V binding contribution to the $\mathrm{O}$ 1s level compared to the O-La one seems to be higher, which could be explained by the possible presence of vanadium oxides $\mathrm{VO}_{x}$ at least at the surface of the V-richer samples. The effect is predominant from a ratio of 1.22 . Secondly, a shift from 528.8 to $529.4 \mathrm{eV}$ of the O-La contribution is observed for ratios higher than 1.22 (Figure 6.a and 6.b). This difference is attributed to the presence of $\mathrm{La}_{2} \mathrm{O}_{3}$ which appears with this high ratio as confirmed by XRD measurements meaning that the O-La contribution shift could be attributed to the $\mathrm{La}_{2} \mathrm{O}_{3}$ phase apparition and 


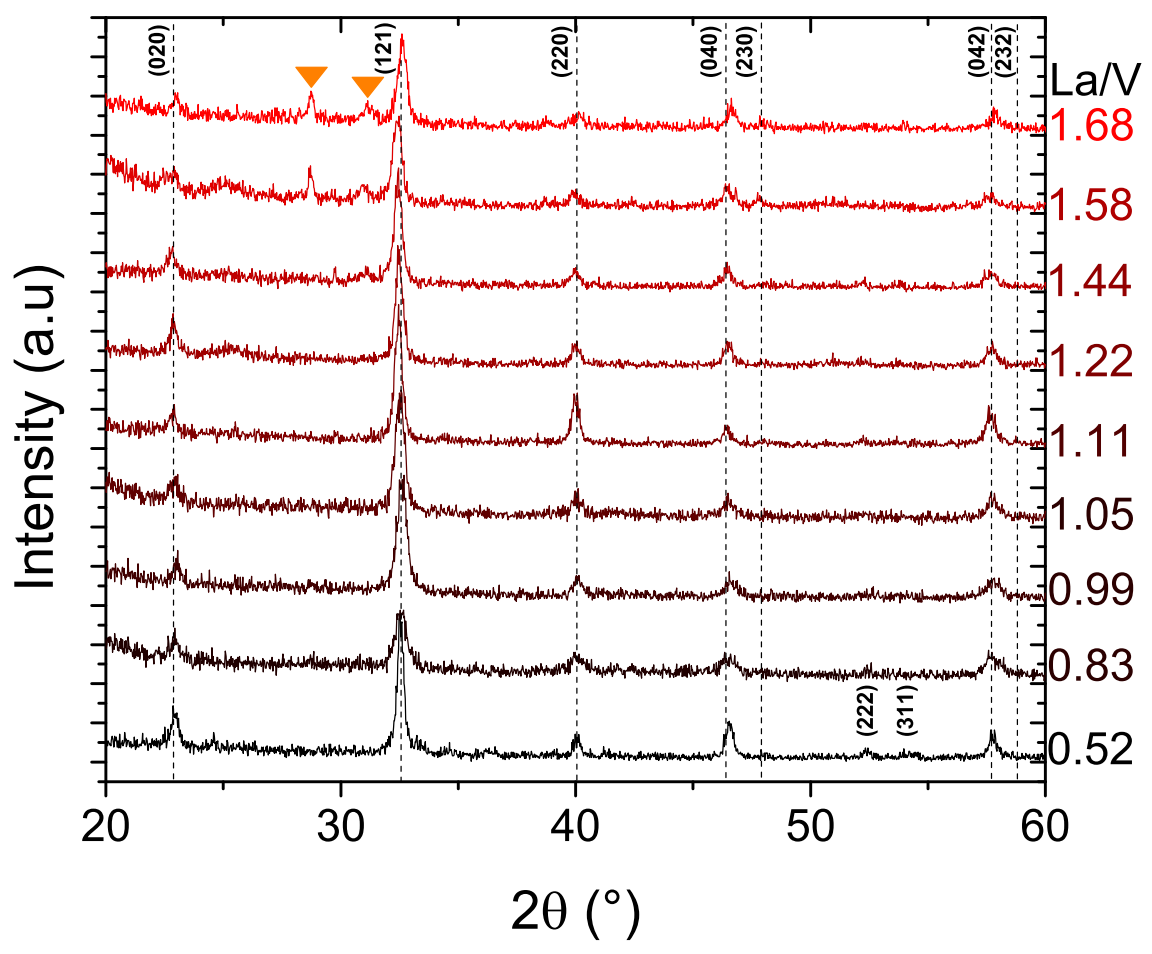

Figure 5: X-ray diffractogram in $2 \theta$ geometry of samples elaborated for different La/V atomic ratio. Two new peaks are appearing with the lanthanum richer samples (see the two orange triangles) which can be attributed to the $\mathrm{La}_{2} \mathrm{O}_{3}$ cubic structure.

not associated with a variation of the La-O coordination among the $\mathrm{LaVO}_{3}$ perovskite phase. The signal corresponding to the perovskite phase is shifted around $0.6 \mathrm{eV}$ compared to $\mathrm{La}_{2} \mathrm{O}_{3}$.

The evolution of the La $3 \mathrm{~d}$ signal for the different La/V ratios is reported in Figure 7.a. The signal exhibits a doublet due to the splitting of La 3 d into $5 / 2$ and $3 / 2$ contributions. Then, a second multiplet splitting is observed in each contribution, that is attributed to the interatomic charge transfer of the $\mathrm{O} 2 \mathrm{p}$ to La $4 \mathrm{f}$ level, by the shake-up process, that ends in $3 \mathrm{~d}^{9} \mathrm{f}^{1}$ final state $[30,31]$. The delta between these two contributions (main peak and satellite) is widely dependent on the species, and may vary in a wide range (from 3.37 to $4.27 \mathrm{eV}$, see [32]), while the main peak position is only slightly affected [33]. The plot of the energy difference $\Delta E$ between the main contribution of La $3 \mathrm{~d}_{5 / 2}$, centered at $833.6 \mathrm{eV}$, and its satellite is shown in Figure 7.b. The evolution 
(a)

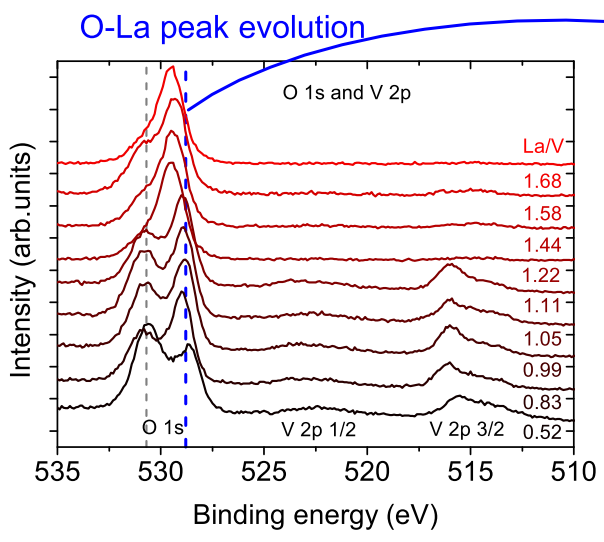

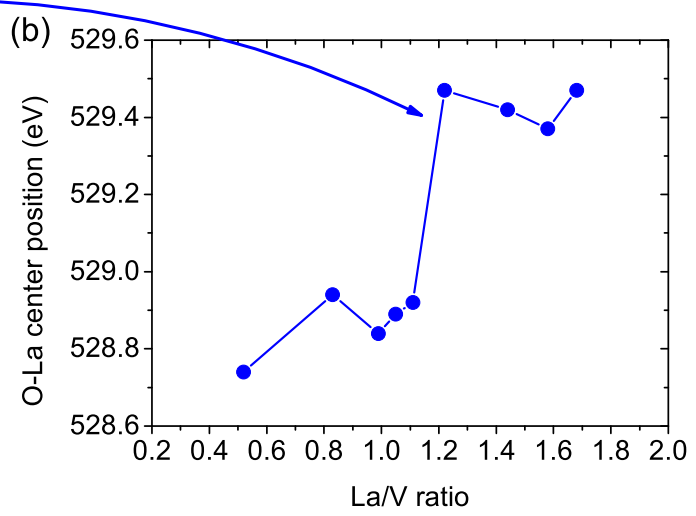

(c)

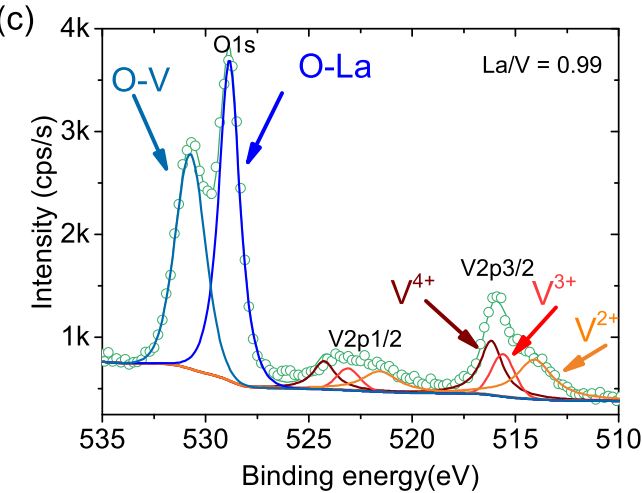

Figure 6: O1s and V2p core level spectra for sample with different La/V ratio (a). Evolution of the O-La binding energy as a function of the different La/V ratio (b). Example of peak fitting with the six contributions of V2p signal and the two contribution of O1s signal (c).

confirms the previous observation, with a drop of $\Delta \mathrm{E}$ from 3.71 to $3.57 \mathrm{eV}$, when the atomic ratio reach 1.22 or higher values. As previously, this drop is attributed to the apparition of $\mathrm{La}_{2} \mathrm{O}_{3}$.

In order to see the effect of the La/V ratio variation, cell parameters refinements were performed (Fullprof Suite). Figure 8 presents the cell-volume evolution with the La/V ratio obtained after the refinement (varying from 233 to $241 \AA^{3}$ with an error of almost $4 \AA^{3}$ ). The refined volume does not evolve with this two-step synthesis in opposition to films obtained by molecular beam epitaxy [6] where the out-of-place parameter decreases when La/V ratio differs from one. In our case, this means that all the lanthanum in excess introduced in the lanthanum-richer samples is not incorporated in the $\mathrm{LaVO}_{3}$ phase but in the $\mathrm{La}_{2} \mathrm{O}_{3}$ phase. The mean cell-volume value is $240 \AA^{3}$ 


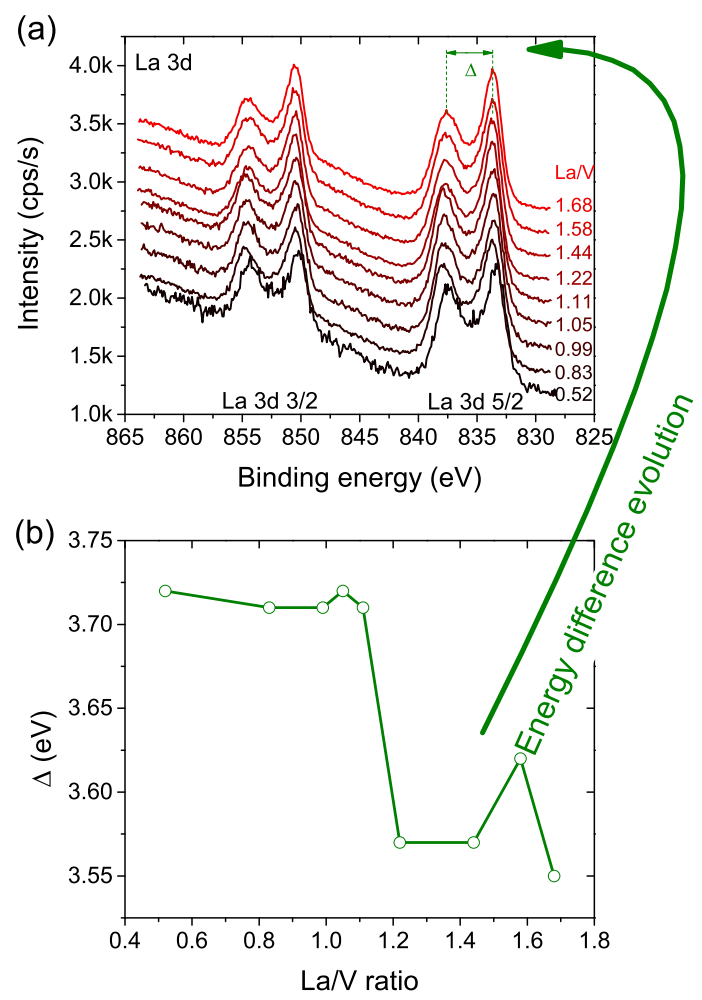

Figure 7: Evolution of the XPS La 3d spectra with the different La/V atomic ratio (a), and evolution of the energy gap between the two contributions of La $3 \mathrm{~d} 5 / 2$ (b).

close to the $242 \AA^{3}$ value calculated with the cell-parameters found by Bordet et al. [34].

In addition to chemical and structural investigation, a study of infrared properties has been carried out (Figure 9). Three major peaks are visible at $17.9 \mu \mathrm{m}\left(559 \mathrm{~cm}^{-1}\right), 27.9 \mu \mathrm{m}\left(358 \mathrm{~cm}^{-1}\right)$ and $59.9 \mu \mathrm{m}\left(166 \mathrm{~cm}^{-1}\right)$ attributed to the three vibration modes of the perovskite, namely $\mathrm{V}-\mathrm{O}$ stretching, V-O-V bending and La translation respectively [35]. These vibration modes are not affected by stoichiometry variations. However, the La/V ratio modification leads to the appearance of a peak at $11.13 \mu \mathrm{m}\left(885 \mathrm{~cm}^{-1}\right)$ attributed to La-O-Si vibration mode [36] and suggests a different structure at the interface with the silicon substrate. A slight contribution at $20.5 \mu \mathrm{m}\left(487 \mathrm{~cm}^{-1}\right)$ appears for La/V ratio of 0.52 and may be attributed to a vanadium oxide. FTIR spectra thus confirm the XPS and XRD analyses with $\mathrm{LaVO}_{3}$-type formation without additional phases for $\mathrm{La} / \mathrm{V}$ ratio ranging from somewhere between 0.52 and 0.83 up to a ratio of 1.22 . 


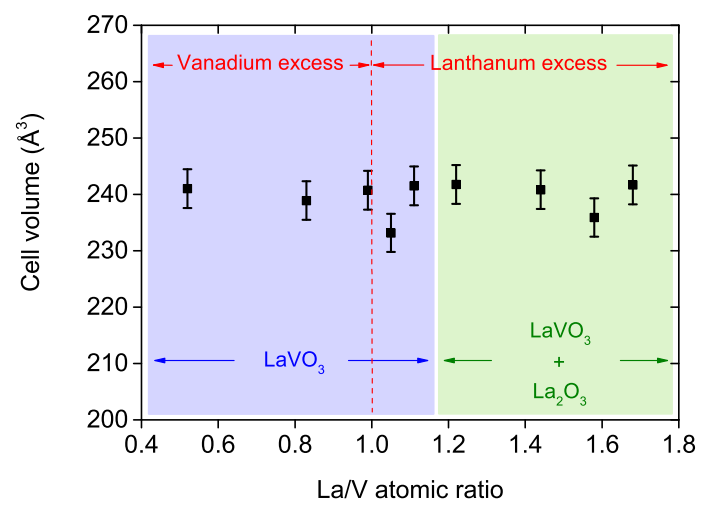

Figure 8: Evolution of the orthorhombic unit cell-volume with the La/V atomic ratio. The red dashed-line distinguishes the vanadium or lanthanum-richer samples while the blue and green boxes give the structures in presence.

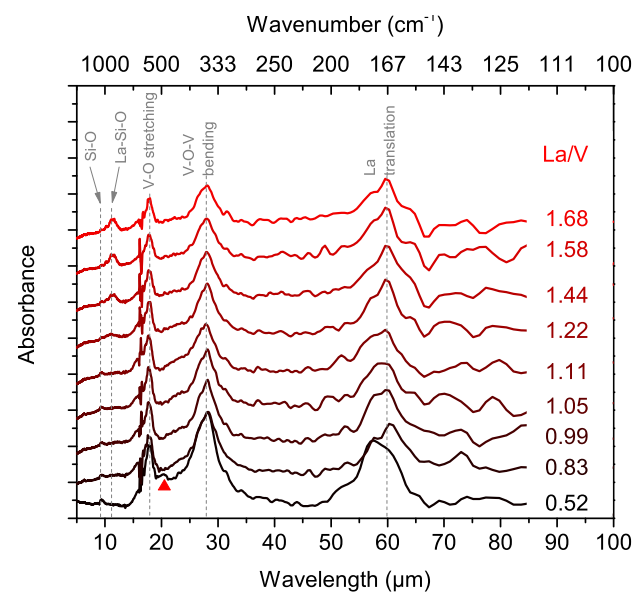

Figure 9: Absorbance of $\mathrm{La}_{x} \mathrm{~V}_{y} \mathrm{O}_{3}$ films at different La/V ratios.

XRD diffractograms in Figure 5 reveal the presence of $\mathrm{La}_{2} \mathrm{O}_{3}$ cubic structure and the XPS spec-

tra shown in Figure 6 reveal the $2 \mathrm{p}_{3 / 2}$ vanadium contribution extinguishment with increasing $\mathrm{La} / \mathrm{V}$ atomic ratio. Those facts are motivating a TEM investigation in order to locate both structures and element positions using respectively fast Fourier transforms of HRTEM images or EELS analyses on three FIB lamellae and both cut using the FIB technique; the first for the V-richer sample with a $\mathrm{La} / \mathrm{V}$ ratio of 0.52 , the second for the $\mathrm{La} / \mathrm{V}=0.99$ sample closest to the stoichiometry and the third for the lanthanum-richer $\mathrm{La} / \mathrm{V}=1.68$ sample. 
Several STEM images have been taken with the high angle annular dark field (HAADF) detector in order to select regions for EELS spectrum acquisitions. Figure 10 exhibits the presence of carbon and platinum elements, both used for lamella preparation. Between the lanthanum-vanadiumoxygen film and the silicon substrate, we detect a thin silica film corresponding to native silicon oxide.

Figure 10 shows two HAADF cross-section images and for selected regions, the corresponding elemental maps of lanthanum $\mathrm{M}_{4,5}$ edges and vanadium $\mathrm{L}_{2,3}$ edges. Colored intensities depend on the area of the selected characteristic energy-loss peaks and respectively correspond to lanthanum $\mathrm{M}_{4}$ or vanadium $\mathrm{L}_{3}$ rays among the different EELS spectra acquired for each pixel of the maps. Then intensities are proportional to the elemental contents. The right color bar representing the total signal of the lanthanum and vanadium EELS peak intensities (in cyan color in the Figure 10.a, 10.b and 10.c) seems to have the same brightness on the whole thickness of the sample with a La/V ratio close to 0.52 (Figure 10.a) meaning that both vanadium and lanthanum are present whatever the depth in the film. Nevertheless, the EELS spectra shown at the right of the figure clearly brings out a region where there is less lanthanum than the others. In the case of the sample with a $\mathrm{La} / \mathrm{V}$ ratio close to 1 (see Figure 10.b) the right color bar has an almost constant brightness except for the film-substrate border where a lake of vanadium which is confirmed by the lower EELS spectrum at the right of the same figure is observed on a thickness smaller than $3 \mathrm{~nm}$ (where the total film thickness is close to $260 \mathrm{~nm}$ ). However, for the La-rich sample with a ratio near 1.68 and a total film thickness close to $192 \mathrm{~nm}$, the total signal (shown in Figure 10.b) highlights a lake of vanadium close to the film borders, namely up to approximately $6 \mathrm{~nm}$ in depth at the surface and $35 \mathrm{~nm}$ at the layer-substrate interface, which represents almost 20 percents of the total film thickness could be a potential localization for the formation of $\mathrm{La}_{2} \mathrm{O}_{3}$.

In order to study the crystallographic structure, Fast Fourier Transforms (FFT) on HRTEM images or diffraction patterns (not shown) were recorded on different crystallites. As expected, for the $\mathrm{La} / \mathrm{V}=0.99$, only the $\mathrm{LaVO}_{3}$ phase was found. For the lanthanum-deficient sample with the $\mathrm{La} / \mathrm{V}$ ratio of 0.52 , we have only observed the $\mathrm{LaVO}_{3}$ phase, despite that the regions with less lanthanum were revealed by EELS for this V-richer sample (see Figure 10.a) and even more, that a signature of vanadium oxides was visible when using on the infrared spectrum (see Figure 9).

225 This fact could be explained by small crystallite sizes of the potential vanadium oxides. On the other hand, for the $\mathrm{La} / \mathrm{V}=1.68$ sample, at the surface (interface between the layer and the carbon, 
Figure 10.b) we found $\mathrm{La}_{2} \mathrm{O}_{3}$ cubic crystallites (using lattice parameters given in [24]) for almost three nanometers i.e. approximately the thickness without vanadium found using EELS. At the center of the layer only $\mathrm{LaVO}_{3}$ orthorhombic crystallites were identified, surrounded by amorphous domains. The transition between $\mathrm{La}_{2} \mathrm{O}_{3}$ and $\mathrm{LaVO}_{3}$ regions is not abrupt since a mixture of $\mathrm{La}_{2} \mathrm{O}_{3}$ and a very few $\mathrm{LaVO}_{3}$ orthorhombic crystallites (identified with lattice parameters of [23]) is present on a thickness of three nanometers despite the low vanadium EELS signal (EELS signal in Figure 10.b). Finally, close to the native silica between the film and the substrate we only detected the presence of the $\mathrm{La}_{2} \mathrm{O}_{3}$ cubic structure too. Another surprising fact is the presence of silicon from the substrate at the interfaces but only for this sample, with a large lanthanum excess which is not occurring before annealing. This fact may be attributed to the possible insertion of the silicon into the $\mathrm{La}_{2} \mathrm{O}_{3}$ structure that is confirmed by a La-O-Si infrared vibration mode (Figure 9). The $\mathrm{La}_{2} \mathrm{O}_{3} / \mathrm{LaVO}_{3}$ non negligible thickness ratio close to $20 \%$ justifies the $\mathrm{La}_{2} \mathrm{O}_{3}$ phase present at the surface and the interface revealed by XRD, XPS and FTIR.

To summarize, the growth window of $\mathrm{LaVO}_{3}$ structure ranges from $\mathrm{La} / \mathrm{V}$ ratio around 0.5 up to 1.7. The increase of the lanthanum content induces the formation of $\mathrm{La}_{2} \mathrm{O}_{3}$ phase containing silicon at each perovskite film boundaries whereas when increasing the vanadium concentration, vanadium oxides seem to be present in volume, where a lake of lanthanum was observed.

\section{Conclusion}

The $\mathrm{LaVO}_{3}$ growing window has been investigated by the means of $\mathrm{La}_{x} \mathrm{~V}_{y} \mathrm{O}_{3}$ thin films synthesis, by using three complementary characterization methods. The thin films have been elaborated using a two-step method based on the magnetron co-sputtering followed by an ex-situ reducing thermal treatment (under $\mathrm{Ar} / \mathrm{H}_{2}$ mixture). Surprisingly, the structure presents a high tolerance, even using an annealing step. FTIR, XPS and XRD analyses clearly demonstrate structural modifications at $\mathrm{La} / \mathrm{V}$ ratios higher than 1.2 whereas for the $\mathrm{La} / \mathrm{V}$ ratio of 0.52 the FTIR highlights a new vibration mode, related to the presence of vanadium oxide(s). According to TEM and FTIR observations, vanadium oxide crystallites are present in volume contrary to the $\mathrm{La}_{2} \mathrm{O}_{3}$ lanthanum oxide observed at the interface meaning that in the case of a vanadium excess no oxide layer is preferentially formed at the interfaces. This is an interesting fact for photovoltaics applications because stabilizing an unique crystallographic structure means a constant and stable $1.1 \mathrm{eV}$ indirect optical gap in such materials and also since the presence of the $\mathrm{La}_{2} \mathrm{O}_{3}$ oxide at the interfaces (out of the determined 
growth window) could affect the physical properties of a solar cell [37]. Furthermore, the use of magnetron sputtering makes up-scalable process over a large surface possible for example in the solar panels realization. or not-for-profit sectors.

\section{References}

[1] E. Manousakis, Photovoltaic effect for narrow-gap Mott insulators, Physical Review B 82 (12) (2010) 125109. doi:10.1103/PhysRevB.82.125109. URL https://link.aps.org/doi/10.1103/PhysRevB.82.125109

[2] T. Arima, Y. Tokura, J. B. Torrance, Variation of optical gaps in perovskite-type 3d transitionmetal oxides, Physical Review B 48 (23) (1993) 17006.

URL https://journals.aps.org/prb/abstract/10.1103/PhysRevB.48.17006

[3] W. Shockley, H. J. Queisser, Detailed Balance Limit of Efficiency of p-n Junction Solar Cells, Journal of Applied Physics 32 (3) (1961) 510-519. doi:10.1063/1.1736034.

URL http://aip.scitation.org/doi/abs/10.1063/1.1736034

[4] E. Assmann, P. Blaha, R. Laskowski, K. Held, S. Okamoto, G. Sangiovanni, Oxide Heterostructures for Efficient Solar Cells, Physical Review Letters 110 (7) (2013) 078701. doi: 10.1103/PhysRevLett.110.078701.

URL https://journals-aps-org.bases-doc.univ-lorraine.fr/prl/abstract/10.1103/ PhysRevLett.110.078701

[5] H.-T. Zhang, L. R. Dedon, L. W. Martin, R. Engel-Herbert, Self-regulated growth of $\mathrm{LaVO}_{3}$ thin films by hybrid molecular beam epitaxy, Applied Physics Letters 106 (23) (2015) 233102. 
doi : 10.1063/1.4922213.

[6] H.-T. Zhang, M. Brahlek, X. Ji, S. Lei, J. Lapano, J. W. Freeland, V. Gopalan, R. EngelHerbert, High-Quality $\mathrm{LaVO}_{3}$ Films as Solar Energy Conversion Material, ACS Applied Materials \& Interfaces 9 (14) (2017) 12556-12562. doi:10.1021/acsami.6b16007.

URL http://dx.doi.org/10.1021/acsami.6b16007

[7] H. Rotella, U. Lders, P.-E. Janolin, V. H. Dao, D. Chateigner, R. Feyerherm, E. Dudzik, W. Prellier, Octahedral tilting in strained $\mathrm{LaVO}_{3}$ thin films, Physical Review B 85 (18) (2012) 184101. doi:10.1103/PhysRevB.85.184101.

URL https://link.aps.org/doi/10.1103/PhysRevB.85.184101

[8] W. Choi, T. Sands, K. Kim, Epitaxial growth of semiconducting $\mathrm{LaVO}_{3}$ thin films, Journal of Materials Research 15 (2000) 1-3. doi:10.1557/JMR.2000.0001.

URL http://adsabs.harvard.edu/abs/2000JMatR . 15 ...1C

[9] Q. Wang, K. Itaka, H. Minami, H. Kawaji, H. Koinuma, Combinatorial pulsed laser deposition and thermoelectricity of $\left(\mathrm{la}_{1 x} \mathrm{ca}_{x}\right) \mathrm{VO}_{3}$ composition-spread films, Science and Technology of Advanced Materials 5 (5) (2004) 543-547. doi:10.1016/j.stam.2004.03.003. URL http://www.sciencedirect.com/science/article/pii/S1468699604000804

[10] L. F. Kourkoutis, D. A. Muller, Y. Hotta, H. Y. Hwang, Asymmetric interface profiles in $\mathrm{LaVO}_{3} \mathrm{SrTiO}_{3}$ heterostructures grown by pulsed laser deposition, Applied Physics Letters 91 (16) (2007) 163101. doi:10.1063/1.2798060.

URL https://aip.scitation.org/doi/10.1063/1.2798060

[11] W. Sheets, B. Mercey, W. Prellier, Effect of charge modulation in $\left(\mathrm{LaVO}_{3}\right)_{m}\left(\mathrm{SrVO}_{3}\right)_{n}$ superlattices on the insulator-metal transition: Applied Physics Letters: Vol 91, No 19, Applied Physics Letters 91 (19). doi:10.1063/1.2805222.

URL https://aip.scitation.org/doi/abs/10.1063/1.2805222?journalCode=apl

[12] M. Jellite, J. L. Rehspringer, M. A. Fazio, D. Muller, G. Schmerber, G. Ferblantier, S. Colis,

A. Dinia, M. Sugiyama, A. Slaoui, D. Cavalcoli, T. Fix, Investigation of $\mathrm{LaVO}_{3}$ based compounds as a photovoltaic absorber, Solar Energy 162 (2018) 1-7. doi:10.1016/j.solener. 
2017.12 .061$.

URL https://www.sciencedirect.com/science/article/pii/S0038092X1731143X

[13] D. Mercs, A. Didelot, F. Capon, J.-F. Pierson, B. Hafner, A. Pazidis, S. Fste, R. Reineke-Koch, Innovative Smart Selective Coating to Avoid Overheating in Highly Efficient Thermal Solar Collectors, Energy Procedia 91 (2016) 84-93. doi:10.1016/j.egypro.2016.06.177. URL http://www.sciencedirect.com/science/article/pii/S1876610216302752

[14] E. Haye, V. Pierron, S. Barrat, F. Capon, F. Munnik, S. Bruyère, Nitrogen redistribution in annealed $\mathrm{LaFeO}_{x} \mathrm{~N}_{y}$ thin films investigated by FTIR spectroscopy and EELS mapping, Applied Surface Science 427 (2018) 1041-1045. doi:10.1016/j.apsusc. 2017.09.090.

URL http://www.sciencedirect.com/science/article/pii/S0169433217327393

[15] E. Haye, S. Bruyere, E. André, P. Boulet, S. Barrat, F. Capon, P. Miska, S. Migot, C. Carteret, R. Coustel, C. Gendarme, S. Diliberto, F. Munnik, $\mathrm{LaFeO}_{x} \mathrm{~N}_{y}$ perovskite thin films: Nitrogen location and its effect on morphological, optical and structural properties, Journal of Alloys and Compounds 724 (2017) 74 -83. doi:10.1016/j.jallcom.2017.07.025.

URL https://hal.univ-lorraine.fr/hal-01767763

[16] E. Haye, F. Capon, S. Barrat, D. Mangin, J.-F. Pierson, Phenomenological study of iron and lanthanum magnetron co-sputtering using two reactive gases, Surface and Coatings Technology 298. doi:10.1016/j.surfcoat.2016.04.039.

[17] E. Haye, F. Capon, S. Barrat, P. Boulet, E. Andre, C. Carteret, S. Bruyere, Properties of rareearth orthoferrites perovskite driven by steric hindrance, Journal of Alloys and Compounds 657 (2016) 631-638. doi:10.1016/j.jallcom.2015.10.135.

URL http://www.sciencedirect.com/science/article/pii/S0925838815313918

[18] F. Capon, A. Boileau, C. Carteret, N. Martin, P. Boulet, J. F. Pierson, Cation size effect on the thermochromic properties of rare earth cobaltites $\mathrm{RECoO}_{3}$ (RE: La, Nd, Sm), Journal of Applied Physics 114 (11) (2013) 113510. doi:10.1063/1.4821884.

URL https://aip-scitation-org.bases-doc.univ-lorraine.fr/doi/full/10.1063/1. 4821884

[19] M. F. Sunding, K. Hadidi, S. Diplas, O. M. Lvvik, T. E. Norby, A. E. Gunns, XPS characterisation of in situ treated lanthanum oxide and hydroxide using tailored charge referencing 
and peak fitting procedures, Journal of Electron Spectroscopy and Related Phenomena 184 (7) (2011) 399-409. doi:10.1016/j .elspec. 2011.04.002.

URL http://www.sciencedirect.com/science/article/pii/S0368204811000727

[20] F. Capon, D. Horwat, J. F. Pierson, V. Chapusot, A. Billard, Strontium-doped lanthanum manganite coatings crystallised after air annealing of amorphous co-sputtered films, Materials Chemistry and Physics 116 (1) (2009) 219-222. doi:10.1016/j.matchemphys.2009.03.021. URL http://www.sciencedirect.com/science/article/pii/S0254058409001631

[21] D. Depla, G. Buyle, J. Haemers, R. De Gryse, Discharge voltage measurements during magnetron sputtering, Surface and Coatings Technology 200 (14) (2006) 4329-4338. doi: 10.1016/j. surfcoat.2005.02.166.

URL http://www.sciencedirect.com/science/article/pii/S0257897205003634

[22] A. Boileau, F. Capon, P. Laffez, S. Barrat, J. L. Endrino, R. E. Galindo, D. Horwat, J. F. Pierson, Mechanisms of Oxidation of $\mathrm{NdNiO}_{3-\delta}$ Thermochromic Thin Films Synthesized by a Two-Step Method in Soft Conditions, The Journal of Physical Chemistry C 118 (11) (2014) 5908-5917. doi:10.1021/jp4111597.

URL https://doi.org/10.1021/jp4111597

[23] H. Seim, H. Fjellvg, B. C. Hauback, A. Gumm, S. Larsen, Non-Stoichiometric $\mathrm{LaVO}_{3}$. II. Powder Neutron Diffraction Study of Crystal and Magnetic Structure for $\mathrm{La}_{1}-x \mathrm{VO}_{3}, 0.00$ $<=\mathrm{X}<=0.10$., Acta Chemica Scandinavica 52 (1998) 1301-1306. doi:10.3891/acta.chem. scand. 52-1301.

URL http://actachemscand.org/doi/10.3891/acta.chem.scand.52-1301

[24] A.-E. Gobichon, J.-P. Auffrdic, D. Lour, Potassium Lanthanum Nitrate System: Phase Equilibria and Thermal and Structural Properties, Journal of Solid State Chemistry 144 (1) (1999) 68-80. doi:10.1006/jssc.1998.8119. URL http://www.sciencedirect.com/science/article/pii/S0022459698981191

[25] M. C. Biesinger, L. W. M. Lau, A. R. Gerson, R. S. C. Smart, Resolving surface chemical states in XPS analysis of first row transition metals, oxides and hydroxides: $\mathrm{Sc}, \mathrm{Ti}, \mathrm{V}, \mathrm{Cu}$ and Zn, Applied Surface Science 257 (2010) 887-898. doi:10.1016/j .apsusc.2010.07.086. URL http://adsabs.harvard.edu/abs/2010ApSS . . 257 . .887B 
[33] S. Han, J. Lee, K. H. Kim, H. Song, W. Kim, S. Kwon, H.-G. Lee, C. Hwang, J. Jeong, J.-S. Kang, Electronic structures of the CMR perovskites $\mathrm{R}_{1-x} \mathrm{~A}_{x} \mathrm{MnO}_{3}(\mathrm{R}=\mathrm{La}, \mathrm{Pr} ; \mathrm{A}=\mathrm{Ca}$,

[27] L. Wang, Y. Li, A. Bera, C. Ma, F. Jin, K. Yuan, W. Yin, A. David, W. Chen, W. Wu, W. Prellier, S. Wei, T. Wu, Device Performance of the Mott Insulator $\mathrm{LaVO}_{3}$ as a Photovoltaic Material, Physical Review Applied 3 (6). doi:10.1103/PhysRevApplied.3.064015.

URL https://link.aps.org/doi/10.1103/PhysRevApplied.3.064015

[28] A. Jana, R. J. Choudhary, D. M. Phase, Mott-Hubbard type insulating nature of epitaxial LaV O 3 thin films, Physical Review B 98 (7) (2018) 075124. doi:10.1103/PhysRevB.98.075124. URL https://link.aps.org/doi/10.1103/PhysRevB.98.075124

[29] H. Wadati, Y. Hotta, M. Takizawa, A. Fujimori, T. Susaki, H. Y. Hwang, Characterization of LaVOx thin films by photoemission spectroscopy, Journal of Applied Physics 102 (5) (2007) 053707. doi:10.1063/1.2775889.

URL http://aip.scitation.org/doi/10.1063/1.2775889

[30] R. Scurtu, G. Nechifor, C. Andronescu, V. Fruth, P. Osiceanu, $\mathrm{La}_{0.8} \mathrm{Sr}_{0.2} \mathrm{Ga}_{0.83} \mathrm{Mg}_{0.17} \mathrm{O}_{3-\delta}$ perovkites investigated by impedance spectroscopy and X-ray photoelectron spectroscopy, U.P.B. Sci. Bull., Series B 76 (2014) 67-76.

[31] K. Bolwin, W. Schnurnberger, G. Schiller, Influence of valence band states on the core hole screening in lanthanide perovskite compounds, Zeitschrift fr Physik B Condensed Matter 72 (2) (1988) 203-209. doi:10.1007/BF01312136.

URL https://link.springer.com/article/10.1007/BF01312136

[32] S. Mickeviius, S. Grebinskij, V. Bondarenka, B. Vengalis, K. liuien, B. A. Orlowski, V. Osinniy, W. Drube, Investigation of epitaxial $\mathrm{LaNiO}_{3-x}$ thin films by high-energy XPS, Journal of Alloys and Compounds 423 (1) (2006) 107-111. doi:10.1016/j.jallcom.2005.12.038. URL http://www.sciencedirect.com/science/article/pii/S0925838805019171 
Sr, Ce) using photoelectron spectroscopy, Journal of the Korean Physical Society 40 (2002) $501-510$.

[34] P. Bordet, C. Chaillout, M. Marezio, Q. Huang, A. Santoro, S.-W. Cheong, H. Takagi, C. Oglesby, B. Batlogg, Structural Aspects of the Crystallographic-Magnetic Transition in $\mathrm{LaVO}_{3}$ around $140 \mathrm{~K}$, Journal of Solid State Chemistry 106 (2) (1993) 253-270. doi: 10.1006/jssc. 1993.1285 .

URL http://www.sciencedirect.com/science/article/pii/S0022459683712855

[35] E. Haye, E. Andre, F. Capon, S. Barrat, M. De La Pierre, R. Dovesi, C. Carteret, Experimental and Theoretical Infrared Signatures of $\mathrm{REMO}_{3}(\mathrm{RE}=\mathrm{La}, \mathrm{Pr}, \mathrm{Nd}, \mathrm{Sm}$, and $\mathrm{M}=\mathrm{Co}, \mathrm{Fe})$ Perovskites, The Journal of Physical Chemistry C 122 (19) (2018) 10519-10525. doi:10. 1021/acs.jpcc.8b01433.

URL https://doi.org/10.1021/acs.jpcc.8b01433

[36] J. Kwon, M. Dai, M. D. Halls, E. Langereis, Y. J. Chabal, R. G. Gordon, In Situ Infrared Characterization during Atomic Layer Deposition of Lanthanum Oxide, The Journal of Physical Chemistry C 113 (2) (2009) 654-660. doi:10.1021/jp806027m.

URL https://doi.org/10.1021/jp806027m

[37] S. F. Shaikh, H.-C. Kwon, W. Yang, H. Hwang, H. Lee, E. Lee, S. Ma, J. Moon, $\mathrm{La}_{2} \mathrm{O}_{3}$ interface modification of mesoporous $\mathrm{TiO}_{2}$ nanostructures enabling highly efficient perovskite solar cells, Journal of Materials Chemistry A 4 (40) (2016) 15478-15485. doi:10.1039/C6TA05008E. URL https://pubs-rsc-org.bases-doc.univ-lorraine.fr/en/content/ articlelanding/2016/ta/c6ta05008e 

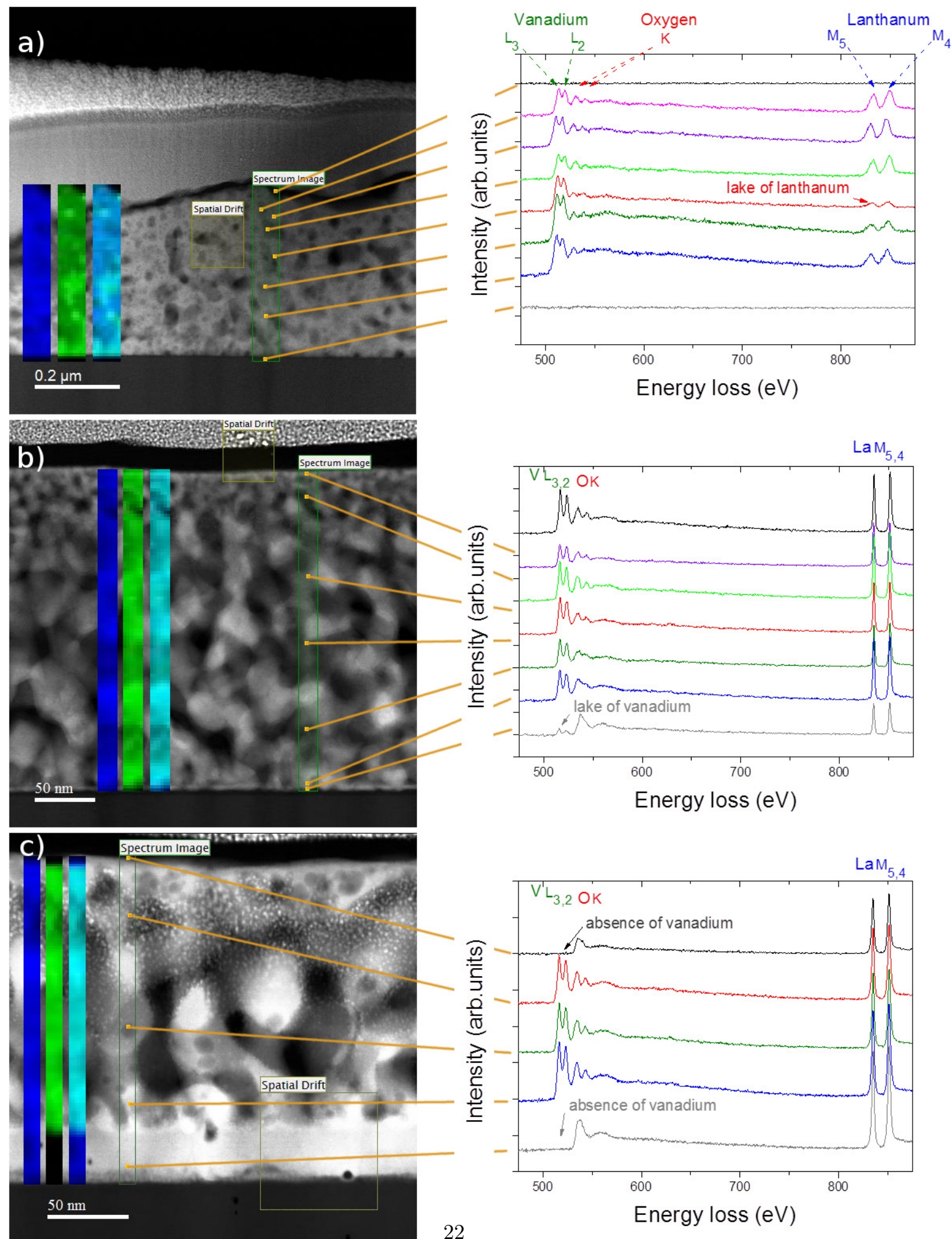

Figure 10: HAADF images of the (a) La/V $=0.52$, (b) La/V $=0.99$ and (c) $\mathrm{La} / \mathrm{V}=1.68$ sample cross-sections. For the selected area an EELS spectrum was taken each 2 nanometers and elemental maps of both lanthanum and vanadium were then constructed with colored intensities; the more bright it is the more the element is present. The "spatial drift" is used for the correction of any sample displacement due to vibration during the measure. 